\title{
Comparative efficacy and safety of axitinib versus sorafenib in metastatic renal cell carcinoma: a systematic review and meta-analysis
}

This article was published in the following Dove Press journal:

OncoTargets and Therapy

8 June 2016

Number of times this article has been viewed

\author{
Hai Wang \\ Libo Man \\ Guizhong Li \\ Guanglin Huang \\ Jianwei Wang
}

Department of Urology, Beijing Jishuitan Hospital, Beijing, People's Republic of China
Correspondence: Hai Wang

Department of Urology, Beijing Jishuitan Hospital, No 3I, East Xinjiekou Street,

Xicheng District, I00035, Beijing,

People's Republic of China

Tel +861058398240

$\mathrm{Fax}+86 \quad 1058398240$

Email wanghai73@sina.com
Objective: This study was performed to evaluate the comparative efficacy and safety of axitinib and sorafenib in the therapy of metastatic renal cell carcinoma.

Materials and methods: Eligible studies were searched from PubMed, Embase, and Future Medicine databases. The pooled hazard ratios and relative risk ratios (RRs) were calculated by using Stata 12.0 software.

Results: A total of 1,011 patients qualified to participate in this Phase III study that included randomized controlled trials. Meta-analysis results showed that axitinib was more highly and significantly associated with a survival benefit in the independently assessed progression-free survival in comparison to sorafenib. The values of $\mathrm{RR}$ of the objective response rate and disease control rate were also significantly different. Results of the analysis of adverse events concerning hypertension and hypothyroidism demonstrated that the values of RR were significantly higher in the axitinib group and lower risks were established in the patients treated with axitinib.

Conclusion: Therefore, axitinib was a better treatment option for metastatic renal cell carcinoma treatment than sorafenib, especially after failure of prior systemic therapies. This analysis revealed that axitinib had higher risks of hypertension and hypothyroidism and lower risks of rash and palmar-plantar erythrodysesthesia.

Keywords: metastatic renal cell carcinoma, progression-free survival, efficacy, adverse events, axitinib, sorafenib, phase III study

\section{Introduction}

Renal cell carcinoma (RCC) is the most common cancer of the kidneys, with $\sim 61,000$ new cases reported annually. ${ }^{1}$ Clear cell RCC is the most predominant subtype and accounts for $70 \%-75 \%$ of all RCC cases. ${ }^{2}$ However, $\sim 30 \%$ of the patients with RCC have overt metastases, and these cases are defined as metastatic RCC (mRCC). ${ }^{3}$ The prognosis of patients with $\mathrm{mRCC}$ remains poor, and the average 5-year survival rate is only $12 \%{ }^{1}$

For many years, the main option for treatment of $\mathrm{mRCC}$ was cytokine therapy combined with either interleukin-2 (IL-2) or interferon alpha (IFN- $\alpha$ ) administration. These treatments had poor efficacy and highly toxic effects. ${ }^{4,5}$ A growing body of evidence indicates that molecular mechanisms are associated with the pathogenesis of mRCC. Targeted agents as a new class of drugs have better potential efficacy and fewer adverse events (AEs) than immunotherapy. ${ }^{6,7}$ Recently, several novel targeted agents, including sorafenib, bevacizumab (plus IFN- $\alpha$ ), temsirolimus, sunitinib, pazopanib, everolimus, and axitinib, have been assessed in large randomized controlled trials (RCTs) in both the first- and second-line settings. ${ }^{8}$ The results of these clinical trials 
have revealed superior progression-free survival (PFS) and overall survival (OS) in comparison with the levels of these indicators in treatments with targeted agents and immunotherapy or placebo. Subsequently, institutions, such as the European Association of Urology Guideline Group, have updated clinical practice guidelines. ${ }^{9,10}$

However, the comparative efficacy and safety of axitinib with sorafenib in the treatment of $\mathrm{mRCC}$ remains to be determined. We performed a meta-analysis using the published articles to investigate the outcomes, efficacy, and safety profiles of axitinib versus sorafenib in patients with mRCC.

\section{Materials and methods}

\section{Relevant articles search strategy}

All available literature sources written in English were searched from the PubMed, Embase, and Future Medicine databases using the key words "(advanced renal carcinoma OR renal cancer OR advanced RCC OR metastatic RCC) AND (sorafenib) AND (axitinib) AND (clinical trial)" up to October 2015.

Studies were included if they met the following criteria: they were restricted to RCTs; compared axitinib with sorafenib; the patients were diagnosed with $\mathrm{mRCC}$ or advanced RCC; and the minimum number of patients enrolled into each group was 50 . The primary outcomes of interest were PFS, OS, objective response rate (ORR), or AEs.

\section{Data extraction}

The following information was extracted from all eligible studies: first author's name, published year, median age, trial phase, number of enrolled patients, median PFS (months), median PFS, median OS (months), median OS, the number of objective response, and the number of AEs. The ORR consisted of the objective response rate, which included complete and partial responses; disease control rate involved objective response rate and stable disease rate. AEs of all grades included diarrhea, hypertension, fatigue, decreased appetite, weight decreased, asthenia, hypothyroidism, rash, nausea, and palmar-plantar erythrodysesthesia. The RCT was evaluated using the Jadad scale, including the randomization, double-blinding, and withdrawals; the final score reported was between 0 and $5 .{ }^{11} \mathrm{~A}$ trial with a score equal to or above 3 was considered to be of high quality according to the Jadad scale.

\section{Statistical analysis}

The hazard ratios (HRs) and their 95\% confidence intervals (CIs) of survival data (PFS and OS) were extracted from the original literature and were calculated to evaluate the outcomes of therapeutic trials. The relative risk ratios (RRs) with $95 \%$ CIs were determined to evaluate the efficacy and safety of the treatment with both drugs. The heterogeneity of the studies in the meta-analysis was assessed using the $I^{2}$ metric and a chi-square test. ${ }^{12}$ A random-effect model was used for the meta-analysis with large heterogeneity $\left(I^{2} \geq 50 \%\right.$ and a chi-square test with $P \leq 0.1$ ); otherwise, the fixedeffects model was used. ${ }^{13}$ Publication bias was evaluated by the Egger tests with substantial heterogeneity. ${ }^{14}$ Data were extracted from the original studies and assessed via Stata 12.0 software (StataCorp LP, College Station, TX, USA). P-value of $<0.05$ was considered statistically significant.

\section{Results}

\section{Study characteristics}

A primary literature search found a total of 322 potentially relevant studies, which were identified and reviewed. A total of three RCTs meeting the inclusion criteria were subjected to statistical analyses. The main reasons for exclusion were meta-analyses or reviews, duplicate publications, and studies evaluating nonclinical outcomes, efficacy, or safety (Figure 1). These studies were multicenter, Phase III, RCTs, involving a total of 1,011 patients in the meta-analysis, ${ }^{15-17}$ in which the effects of the administration of axitinib ( $5 \mathrm{mg}$ bid) were compared with those of the treatment with sorafenib (400 mg bid). The characteristics of these three trials are listed in Tables 1 and 2.

\section{Meta-analyses of outcomes}

In the meta-analyses, data were recorded and assessed by the fixed-effects model $\left(I^{2}<50 \%\right.$ and a chi-square test with $P>0.1)$ as described later. Two trials that compared the efficacy of axitinib on PFS with that of sorafenib constituted the independent assessment and were either treatment-naive or first-line drugs pretreated. The two studies included 1,011 patients. The result that showed a pooled HR of $0.694(95 \%$ CI: $0.586-0.821 ; P<0.001)$ was significant (Figure 2). The values of HR of each study were treatment-naive mRCC: HR 0.770 (95\% CI: $0.560-1.050)^{15}$ and drugs-pretreated mRCC: HR 0.665 (95\% CI: $0.544-0.812) .{ }^{17}$ One trial reporting 723 patients was pretreated, and a pooled HR of 0.969 was found (95\% CI: $0.800-1.174, P=0.748$ ) for the independently assessed OS (Table 1).

\section{Meta-analyses of efficacy}

The fixed-effects model results indicated no significant heterogeneity $\left(I^{2}<50 \%\right.$ and a chi-square test with $\left.P>0.1\right)$. The above two trials including 1,011 patients were performed 
Articles retrieved through databases search $(n=322)$

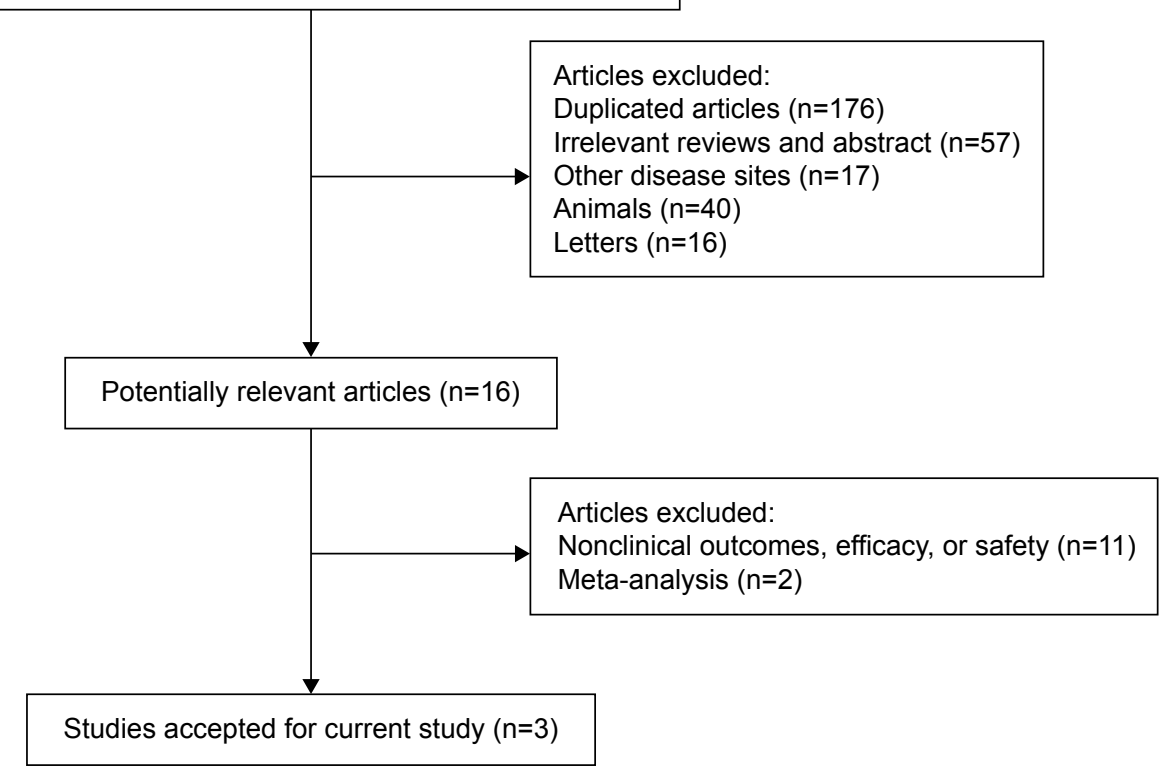

Figure I Flow diagram of the selected studies.

Table I Studies reported HRs for PFS and OS in this meta-analysis

\begin{tabular}{|c|c|c|c|c|c|c|c|c|c|}
\hline First author & $\begin{array}{l}\text { Objective } \\
\text { response } \\
\text { rate }\end{array}$ & Phase & $\begin{array}{l}\text { Median } \\
\text { age (years) } \\
\text { axitinib/ } \\
\text { sorafenib }\end{array}$ & $\begin{array}{l}\text { Dose } \\
\text { axitinib/ } \\
\text { sorafenib }\end{array}$ & $\begin{array}{l}\text { Jadad } \\
\text { scale }\end{array}$ & $\begin{array}{l}\text { Median PFS } \\
\text { (months) } \\
\text { axitinib/ } \\
\text { sorafenib }\end{array}$ & PFS & $\begin{array}{l}\text { Median OS } \\
\text { (months) } \\
\text { axitinib/ } \\
\text { sorafenib }\end{array}$ & OS \\
\hline Rini et al ${ }^{17}$ & 723 & III & $61 / 61$ & $5 / 200 *$ & 3 & $6.7 / 4.7$ & $0.665(0.544-0.812)$ & NA & NA \\
\hline Motzer et al ${ }^{16}$ & 723 & III & $61 / 61$ & $5 / 200 *$ & 3 & NA & NA & $20.1 / 19.2$ & $0.969(0.800-1.174)$ \\
\hline Hutson et al ${ }^{15}$ & 288 & III & $58 / 58$ & $5 / 200 *$ & 3 & $10.1 / 6.5$ & $0.77(0.56-1.05)$ & NA & NA \\
\hline
\end{tabular}

Note: *Indicates mg twice daily.

Abbreviations: HRs, hazard ratios; OS, overall survival; PFS, progression-free survival; NA, not applicable.

Table 2 Efficacy and safety of the included studies

\begin{tabular}{|c|c|c|c|c|}
\hline \multirow[t]{2}{*}{ Efficacy } & \multicolumn{2}{|l|}{ Rini et al ${ }^{17}$} & \multicolumn{2}{|c|}{ Hutson et $\mathbf{a l}^{15}$} \\
\hline & $\begin{array}{l}\text { Axitinib } \\
(\mathbf{N}=36 \mathrm{I}) \\
\mathrm{n}(\%)\end{array}$ & $\begin{array}{l}\text { Sorafenib } \\
(\mathbf{N}=362) \\
n(\%)\end{array}$ & $\begin{array}{l}\text { Axitinib } \\
(\mathbf{N}=192), \\
n(\%)\end{array}$ & $\begin{array}{l}\text { Sorafenib } \\
(\mathrm{N}=96), \\
n(\%)\end{array}$ \\
\hline Objective response rate & $70(19)$ & $34(9)$ & $62(32)$ & $14(15)$ \\
\hline Disease control rate & $250(69)$ & $231(64)$ & $145(76)$ & $65(68)$ \\
\hline Safety & $\begin{array}{l}\text { Axitinib } \\
(\mathrm{N}=359) \\
\mathrm{n}(\%)\end{array}$ & $\begin{array}{l}\text { Sorafenib } \\
(\mathrm{N}=355) \\
\mathrm{n}(\%)\end{array}$ & $\begin{array}{l}\text { Axitinib } \\
(\mathbf{N}=189) \\
n(\%)\end{array}$ & $\begin{array}{l}\text { Sorafenib } \\
(\mathrm{N}=96) \\
\mathrm{n}(\%)\end{array}$ \\
\hline Diarrhea & $197(55)$ & $189(53)$ & $94(50)$ & $38(40)$ \\
\hline Hypertension & $145(40)$ & $103(29)$ & $92(49)$ & $28(29)$ \\
\hline Fatigue & 140 (39) & 112 (32) & $62(33)$ & $25(26)$ \\
\hline Decreased appetite & $123(34)$ & $101(28)$ & $54(29)$ & $18(19)$ \\
\hline Nausea & $116(32)$ & $77(22)$ & $37(20)$ & $14(15)$ \\
\hline Palmar-plantar erythrodysesthesia & $98(27)$ & $18 \mid(5 \mid)$ & $50(26)$ & $37(39)$ \\
\hline Weight decreased & $89(25)$ & $74(21)$ & $69(37)$ & $23(24)$ \\
\hline Asthenia & $74(2 I)$ & $50(14)$ & $39(21)$ & $15(16)$ \\
\hline Hypothyroidism & $69(19)$ & $29(8)$ & $39(21)$ & $7(7)$ \\
\hline Rash & $45(13)$ & $112(32)$ & $18(10)$ & $19(20)$ \\
\hline
\end{tabular}




\begin{tabular}{|c|c|c|}
\hline Study ID & $\operatorname{HR}(95 \% \mathrm{Cl})$ & Weight (\%) \\
\hline Rini et al ${ }^{17}$ & $0.67(0.54-0.81)$ & 71.12 \\
\hline Hutson et al ${ }^{15}$ & $0.77(0.56-1.05)$ & 28.88 \\
\hline Overall $\left(I^{2}=0.0 \%, P=0.441\right)$ & $0.69(0.59-0.82)$ & 100 \\
\hline
\end{tabular}

Figure 2 Forest plot showing the pooled HR from the fixed-effects model for PFS in axitinib vs sorafenib treatments in mRCC patients. Abbreviations: $\mathrm{Cl}$, confidence interval; $\mathrm{HR}$, hazards ratio; $\mathrm{mRCC}$, metastatic renal cell carcinoma; PFS, progression-free survival.

to evaluate the efficacy, including the assessment of indicators, such as the objective response rate and disease control rate. RR obtained in the meta-analysis of the studies for the objective response rate was significant $(\mathrm{RR}=2.12,95 \% \mathrm{CI}$ : 1.55-2.89, $P<0.001$ ) (Figure 3). The RR value obtained in treatment-naive $\mathrm{mRCC}$ was slightly higher $(\mathrm{RR}=2.21$, 95\% CI: 1.31-3.75) than that in drugs-pretreated mRCC ( $R R=2.06,95 \%$ CI: 1.41-3.03) (Figure 3). Meta-analysis showed that the difference in the values of RR was slightly significant in the disease control rate $(\mathrm{RR}=1.09,95 \% \mathrm{CI}$ : $1.00-1.19, P=0.044$ ) (Figure 4). The variations in the values of RR in treatment-naive $\mathrm{mRCC}$ and in drugs-pretreated mRCC were not significant $(\mathrm{RR}=1.12,95 \% \mathrm{CI}$ : 0.95-1.31; $\mathrm{RR}=1.09$, 95\% CI: 0.98-1.20, respectively) (Figure 4).

\section{Meta-analyses of safety}

The fixed-effects model in the current meta-analysis exhibited no significant heterogeneity $\left(I^{2}<50 \%\right.$ and a chi-square test with $P>0.1$ ). Two trials involving 1,011 patients were conducted to assess AEs of all grades (Figures S1-S10). The meta-analysis of hypertensive events and hypothyroidism indicated that $R R$ was significantly higher $(\mathrm{RR}=1.47,95 \%$ CI: $1.23-1.75, P<0.001$; RR $=2.47,95 \%$ CI: $1.72-3.54$, $P<0.001$; respectively) in the axitinib group. The differences between the values of RR in treatment-naive $\mathrm{mRCC}$ and in drugs-pretreated mRCC were significant. Our results revealed that the overall RR of rash and palmar-plantar erythrodysesthesia in the axitinib group were significantly lower than those in the sorafenib group $(\mathrm{RR}=0.41,95 \% \mathrm{CI}$ : $0.31-0.54$, $P<0.001 ; \mathrm{RR}=0.57,95 \% \mathrm{CI}: 0.48-0.67, P<0.001$, respectively). The difference between the values of RR in treatmentnaive $\mathrm{mRCC}$ and in drugs-pretreated $\mathrm{mRCC}$ was significant. Meta-analysis RR value of diarrhea was 1.08 (95\% CI: $0.95-1.22, P=0.231)$. The variations between the values of $\mathrm{RR}$ in treatment-naive $\mathrm{mRCC}$ and in drugs-pretreated $\mathrm{mRCC}$ were not significant. The prevalence of nausea, fatigue, decreased appetite, decreased weight, and asthenia were significantly associated with the treatment in the axitinib group $(\mathrm{RR}=1.46,95 \% \mathrm{CI}: 1.16-1.83, P=0.001 ; \mathrm{RR}=1.24,95 \% \mathrm{CI}$ : $1.04-1.48, P=0.018 ; \mathrm{RR}=1.27,95 \% \mathrm{CI}: 1.04-1.54, P=0.021$; $\mathrm{RR}=1.28,95 \% \mathrm{CI}: 1.03-1.61, P=0.028 ; \mathrm{RR}=1.42,95 \% \mathrm{CI}$ : $1.08-1.88, P=0.014$, respectively). While the values of $\mathrm{RR}$ in

\begin{tabular}{|c|c|c|}
\hline Study ID & RR (95\% Cl) & Weight (\%) \\
\hline Rini et al ${ }^{17}$ & $2.06(1.41-3.03)$ & 64.53 \\
\hline Hutson et $\mathrm{al}^{15}$ & $2.21(1.31-3.75)$ & 35.47 \\
\hline Overall $\left(I^{2}=0.0 \%, P=0.833\right)$ & $2.12(1.55-2.89)$ & 100 \\
\hline
\end{tabular}

Figure 3 Forest plot depicting the pooled RR from the fixed-effects model for objective response rate in axitinib vs sorafenib treatments in mRCC patients. Abbreviations: $\mathrm{Cl}$, confidence interval; $\mathrm{mRCC}$, metastatic renal cell carcinoma; RR, risk ratio. 


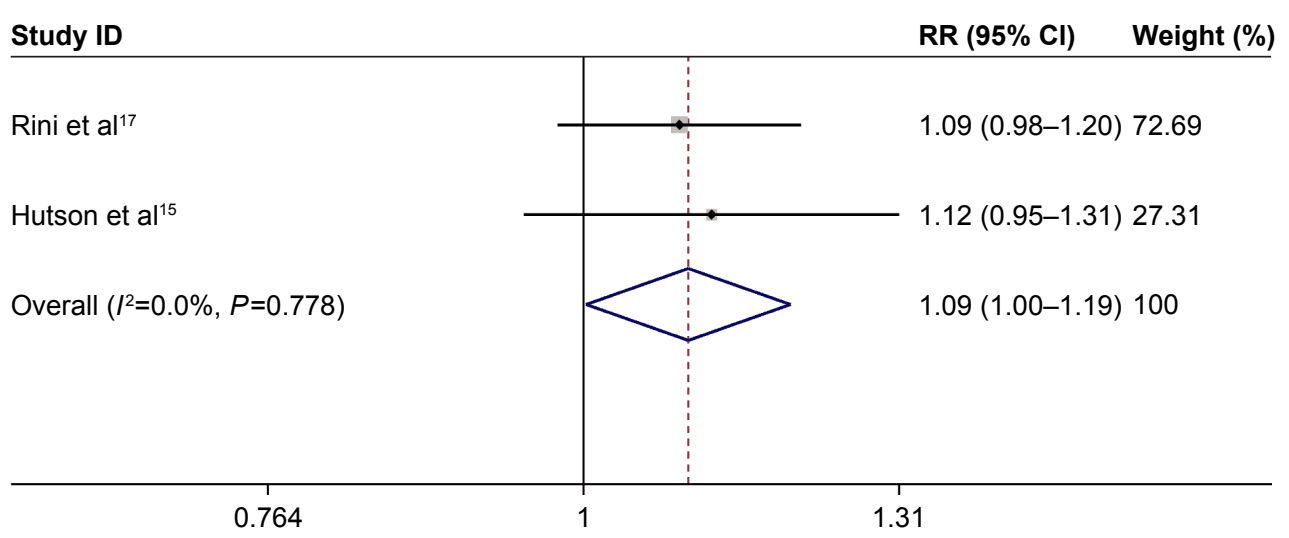

Figure 4 Forest plot illustrating the pooled RR from the fixed-effects model for disease control rate in axitinib vs sorafenib treatments in mRCC patients. Abbreviations: $\mathrm{Cl}$, confidence interval; $\mathrm{mRCC}$, metastatic renal cell carcinoma; RR, risk ratio.

treatment-naive $\mathrm{mRCC}$ were nausea (RR 1.34 CI: 0.76-2.36), fatigue (RR 1.26 CI: 0.85-1.87), decreased appetite (RR 1.52 CI: 0.95-2.45), weight decreased (RR 1.52 CI: 1.02-2.28), and asthenia (RR 1.32 CI: 0.77-2.27); and in drugs-pretreated mRCC were nausea (RR 1.49 CI: 1.16-1.91), fatigue (RR 1.24 CI: 1.01-1.51), decreased appetite (RR 1.20 CI: 0.97-1.50), weight decreased (RR 1.19 CI: 0.91-1.56), and asthenia (RR $1.46 \mathrm{CI}: 1.05-2.03)$.

\section{Discussion}

The results of the present study of axitinib and sorafenib safety and efficacy suggested that treatment with axitinib had a clinical advantage over that with sorafenib. However, the side effect profiles of the targeted agents, such as hypertension, rashes, fatigue, and hypothyroidism needed to be carefully considered in clinical treatment choices. Therefore, we evaluated AEs of all grades in this study.

The pooled analysis found that the administration of axitinib was associated with a considerably higher and statistically significant survival benefit over sorafenib treatment in the independently assessed PFS (HR $=0.694 ; P<0.001)$. Moreover, the patients treated with axitinib had slightly longer median PFS compared to those treated with sorafenib (drugs-pretreated mRCC, 6.7 vs 4.7 months; treatment-naive mRCC, 10.1 vs 6.5 months; respectively). While no improvement was established in PFS for 288 treatment-naive patients ( $\mathrm{HR}=0.770,95 \% \mathrm{CI}: 0.560-1.050),{ }^{15}$ we should be cautious in the interpretation of this result. Although our findings indicated that axitinib application had a significant survival benefit in PFS when compared to that of sorafenib (HR $=0.694$; $P<0.001$ ), we also assume that more well-designed RCTs with larger sample sizes should be conducted to further confirm the relative efficacy of axitinib and sorafenib therapy in patients with treatment-naive mRCC. Additionally, no OS data were presented in the treatment-naive trial. Motzer et $\mathrm{al}^{16}$ reported that the median OS in the axitinib treatment group was not significantly longer than that in the sorafenib treatment group (20.1 vs 19.2 months, respectively). In addition, this result suggested that the treatment with axitinib did not contribute significantly to improvement in OS in comparison with sorafenib $(\mathrm{HR}=0.969 ; P=0.748)$.

Complete response in $\mathrm{mRCC}$ treated with targeted therapy is a rare event; nevertheless, it positively influences the survival. ${ }^{18}$ The percentage of patients reaching complete response in the current study of axitinib and sorafenib efficacy and safety was $0 \% .^{15,17}$ Based on the objective response rate values obtained, the statistical analysis indicated that better efficacy was achieved by the treatment with axitinib compared to treatment with sorafenib $(\mathrm{RR}=2.12 ; P<0.001)$. Moreover, this efficacy in treatment-naive and drugs-pretreated patients was not significantly different $(\mathrm{RR}=2.21,95 \% \mathrm{CI}$ : $1.31-3.75$; $\mathrm{RR}=2.06,95 \%$ CI: 1.41-3.03, respectively). However, slight differences were found between disease control rates of the two treatment groups $(\mathrm{RR}=1.09, P=0.044)$. Therefore, based on the analysis of PFS, objective response rate, and disease control rate, our results further identified better efficacy of the therapy with axitinib in $\mathrm{mRCC}$ patients because of the large sample sizes $(n>1,000)$.

Drug tolerability can influence clinical decisions and should be considered in guiding therapy, because some studies have reported that $\sim 33 \%$ of the patients with $\mathrm{mRCC}$ are lost with each subsequent line of therapy, and only $52 \%$ of the patients with $\mathrm{mRCC}$ receive a second-line or more lines of treatment. ${ }^{19,20}$ In our study, the risks of hypertensive events and hypothyroidism were significantly higher for axitinib (RR $=1.47, P<0.001 ; \mathrm{RR}=2.47, P<0.001$, respectively), whereas the patients treated with axitinib had lower risks of rash and palmar-plantar erythrodysesthesia $(\mathrm{RR}=0.41$, 
$P<0.001 ; \mathrm{RR}=0.57, P<0.001$, respectively). No significant difference in the risk of diarrhea was found between the treatments with the two drugs and mRCC $(P=0.231)$. Nausea, fatigue, decreased appetite, reduced weight, and asthenia were also more prevalent events in the axitinibtreated patients. Interestingly, the risks of nausea, fatigue, and asthenia were slightly higher for axitinib in the drugspretreated group, and only the risk of weight loss was slightly higher for axitinib in the treatment-naive group. Therefore, the results for the risks of nausea, fatigue, decreased appetite, reduced weight, and asthenia need to be confirmed by future studies based on larger sample sizes.

Several limitations of this research were identified. First, three eligible studies were Phase III RCT trials but not double-blind trials; therefore, they can be potential cohort or case-control investigations. Second, selection bias might exist, because the study was limited to the literature sources published in English. Third, the main race of the current study was Caucasians. Other ethnic populations, for example, Asians and Africans, also should be considered in future trials. Fourth, comparative data for patients with nonclear cell histology were absent, and the selection of treatment in these cases remained an issue.

\section{Conclusion}

The current analysis showed that compared with sorafenib, axitinib could provide patients with a clinically significant PFS benefit. Moreover, axitinib was also more effective for mRCC therapy. The analysis of AEs revealed that axitinib posed higher risks of hypertension and hypothyroidism but presented a lower hazard of rash and palmar-plantar erythrodysesthesia. However, based on the findings of a single RCT ( $n=288$ ), we conclude that caution is to be exercised, since axitinib did not confer a survival advantage to patients with treatment-naive MRCC. Therefore, axitinib is a better treatment option for $\mathrm{mRCC}$, especially after failure of prior systemic therapies.

\section{Disclosure}

The authors report no conflicts of interest in this work.

\section{References}

1. Siegel RL, Miller KD, Jemal A. Cancer statistics, 2015. CA Cancer J Clin. 2015;65:5-29.
2. Shuch B, Amin A, Armstrong AJ, et al. Understanding pathologic variants of renal cell carcinoma: distilling therapeutic opportunities from biologic complexity. Eur Urol. 2015;67:85-97.

3. Wersall PJ, Blomgren H, Lax I, et al. Extracranial stereotactic radiotherapy for primary and metastatic renal cell carcinoma. Radiother Oncol. 2005;77:88-95.

4. Negrier S, Perol D, Ravaud A, et al; French Immunotherapy Intergroup. Medroxyprogesterone, interferon alfa-2a, interleukin 2, or combination of both cytokines in patients with metastatic renal carcinoma of intermediate prognosis: results of a randomized controlled trial. Cancer. 2007;110:2468-2477.

5. Negrier S, Escudier B, Lasset C, et al. Recombinant human interleukin-2, recombinant human interferon alfa-2a, or both in metastatic renal-cell carcinoma. Groupe francais d'immunotherapie. N Engl J Med. 1998; 338:1272-1278.

6. Escudier B, Pluzanska A, Koralewski P, et al; Investigators AT. Bevacizumab plus interferon alfa-2a for treatment of metastatic renal cell carcinoma: a randomised, double-blind phase III trial. Lancet. 2007; 370:2103-2111.

7. Motzer RJ, Basch E. Targeted drugs for metastatic renal cell carcinoma. Lancet. 2007;370:2071-2073.

8. Hutson TE. Targeted therapies for the treatment of metastatic renal cell carcinoma: clinical evidence. Oncologist. 2011;16 Suppl 2:14-22.

9. Ljungberg B, Bensalah $\mathrm{K}$, Canfield $\mathrm{S}$, et al. EAU guidelines on renal cell carcinoma: 2014 update. Eur Urol. 2015;67:913-924.

10. Ljungberg B, Cowan NC, Hanbury DC, et al; European Association of Urology Guideline Group. EAU guidelines on renal cell carcinoma: the 2010 update. Eur Urol. 2010;58:398-406.

11. Jadad AR, Moore RA, Carroll D, et al. Assessing the quality of reports of randomized clinical trials: is blinding necessary? Control Clin Trials. 1996;17:1-12.

12. Zintzaras E, Ioannidis JP. Hegesma: genome search meta-analysis and heterogeneity testing. Bioinformatics. 2005;21:3672-3673.

13. Higgins JP, Thompson SG, Deeks JJ, Altman DG. Measuring inconsistency in meta-analyses. BMJ. 2003;327:557-560.

14. Egger M, Davey Smith G, Schneider M, Minder C. Bias in meta-analysis detected by a simple, graphical test. BMJ. 1997;315:629-634.

15. Hutson TE, Lesovoy V, Al-Shukri S, et al. Axitinib versus sorafenib as first-line therapy in patients with metastatic renal-cell carcinoma: a randomised open-label phase 3 trial. Lancet Oncol. 2013;14:1287-1294.

16. Motzer RJ, Escudier B, Tomczak P, et al. Axitinib versus sorafenib as second-line treatment for advanced renal cell carcinoma: overall survival analysis and updated results from a randomised phase 3 trial. Lancet Oncol. 2013;14:552-562.

17. Rini BI, Escudier B, Tomczak P, et al. Comparative effectiveness of axitinib versus sorafenib in advanced renal cell carcinoma (axis): a randomised phase 3 trial. Lancet. 2011;378:1931-1939.

18. Motzer RJ, Bukowski RM. Targeted therapy for metastatic renal cell carcinoma. J Clin Oncol. 2006;24:5601-5608.

19. Levy A, Menard J, Albiges L, et al. Second line treatment of metastatic renal cell carcinoma: the Institut Gustave Roussy experience with targeted therapies in 251 consecutive patients. Eur J Cancer. 2013;49: 1898-1904.

20. Escudier B, Szczylik C, Porta C, Gore M. Treatment selection in metastatic renal cell carcinoma: expert consensus. Nat Rev Clin Oncol. 2012;9: 327-337. 


\section{Supplementary materials}

Study ID

RR $(95 \% \mathrm{Cl}) \quad \%$ weight

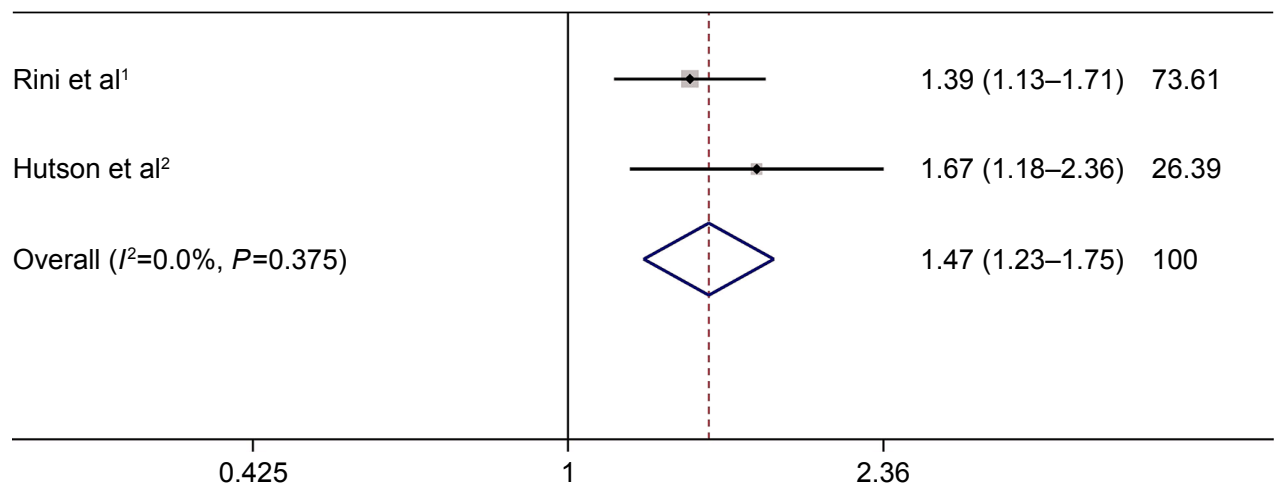

Figure SI Forest plot showing the pooled RR from the fixed-effects model for hypertensive events in axitinib vs sorafenib treatments. Abbreviations: $\mathrm{Cl}$, confidence interval; $\mathrm{RR}$, risk ratio.

Study ID

Rini et al $^{1}$

Hutson et $\mathrm{al}^{2}$

Overall $\left(I^{2}=0.0 \%, P=0.675\right)$
RR $(95 \% \mathrm{Cl}) \quad$ \% weight

$2.35(1.56-3.54) \quad 75.85$

$2.83(1.32-6.09) \quad 24.15$

$2.47(1.72-3.54) \quad 100$

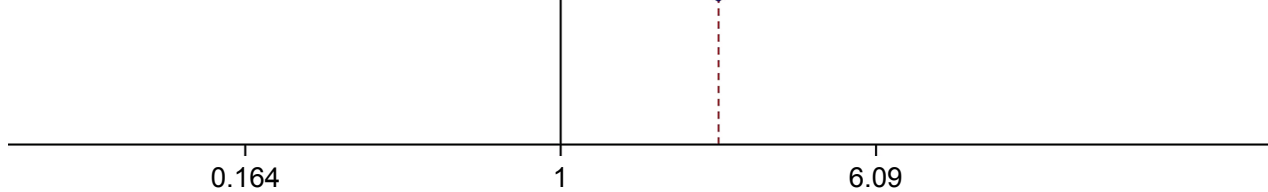

Figure S2 Forest plot displaying the pooled RR from the fixed-effects model for hypothyroidism in axitinib vs sorafenib treatments. Abbreviations: $\mathrm{Cl}$, confidence interval; $\mathrm{RR}$, risk ratio.

\begin{tabular}{|c|c|c|}
\hline Study ID & $\operatorname{RR}(95 \% \mathrm{Cl})$ & $\%$ weight \\
\hline Rini et $\mathrm{al}^{1}$ & $0.40(0.29-0.54)$ & 81.72 \\
\hline Hutson et $\mathrm{al}^{2}$ & $0.48(0.27-0.87)$ & 18.28 \\
\hline Overall $\left(I^{2}=0.0 \%, P=0.577\right)$ & $0.41(0.31-0.54)$ & 100 \\
\hline
\end{tabular}

Figure S3 Forest plot presenting the pooled RR from the fixed-effects model for rash in axitinib vs sorafenib treatments. Abbreviations: $\mathrm{Cl}$, confidence interval; $\mathrm{RR}$, risk ratio. 


\begin{tabular}{|c|c|c|}
\hline Study ID & $\mathrm{RR}(95 \% \mathrm{Cl})$ & $\%$ weight \\
\hline Rini et al ${ }^{1}$ & $0.54(0.44-0.65)$ & 78.76 \\
\hline Hutson et $\mathrm{al}^{2}$ & $0.69(0.49-0.97)$ & 21.24 \\
\hline Overall $\left(I^{2}=32.9 \%, P=0.222\right)$ & $0.57(0.48-0.67)$ & 100 \\
\hline 0.44 & 2.27 & \\
\hline
\end{tabular}

Figure S4 Forest plot illustrating the pooled RR from the fixed-effects model for palmar-plantar erythrodysesthesia in axitinib vs sorafenib treatments. Abbreviations: $\mathrm{Cl}$, confidence interval; $\mathrm{RR}$, risk ratio.

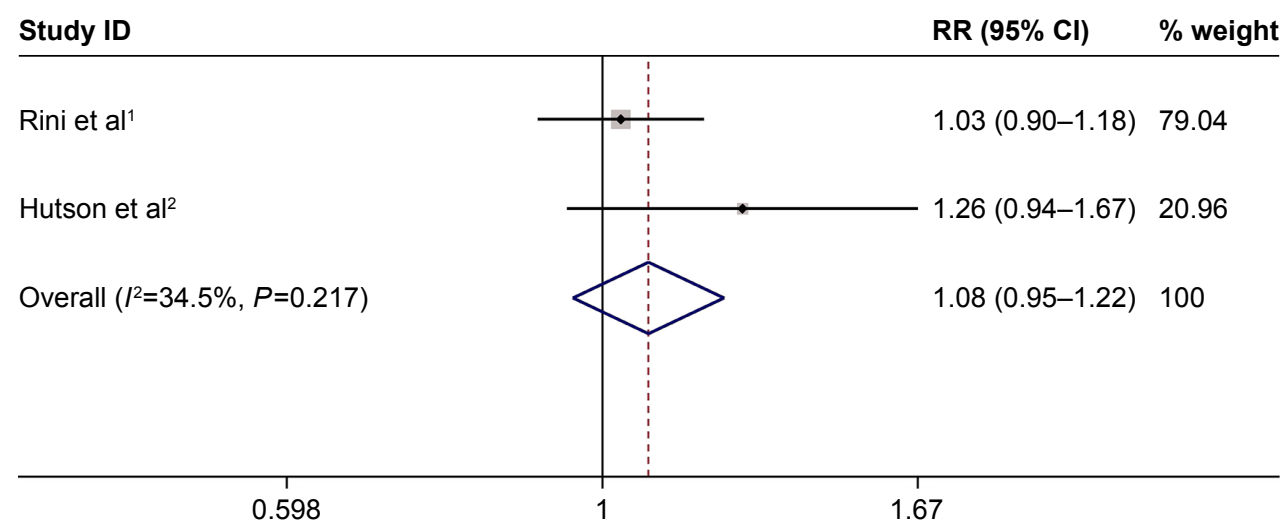

Figure S5 Forest plot depicting the pooled RR from the fixed-effects model for diarrhea in axitinib vs sorafenib treatments.

Abbreviations: $\mathrm{Cl}$, confidence interval; $\mathrm{RR}$, risk ratio.

\begin{tabular}{|c|c|c|}
\hline Study ID & $\operatorname{RR}(95 \% \mathrm{Cl})$ & $\%$ weight \\
\hline Rini et al ${ }^{1}$ & $1.49(1.16-1.91)$ & 80.66 \\
\hline Hutson et $\mathrm{al}^{2}$ & $1.34(0.76-2.36)$ & 19.34 \\
\hline Overall $\left(I^{2}=0.0 \%, P=0.740\right)$ & $1.46(1.16-1.83)$ & 100 \\
\hline
\end{tabular}

Figure S6 Forest plot showing the pooled RR from the fixed-effects model for nausea in axitinib vs sorafenib treatments.

Abbreviations: $\mathrm{Cl}$, confidence interval; $\mathrm{RR}$, risk ratio. 


\begin{tabular}{|c|c|c|}
\hline Study ID & $\operatorname{RR}(95 \% \mathrm{Cl})$ & $\%$ weight \\
\hline Rini et al ${ }^{1}$ & $1.24(1.01-1.51)$ & 77.26 \\
\hline Hutson et $\mathrm{al}^{2}$ & - $1.26(0.85-1.87)$ & 22.74 \\
\hline Overall $\left(I^{2}=0.0 \%, P=0.933\right)$ & $1.24(1.04-1.48)$ & 100 \\
\hline
\end{tabular}

Figure S7 Forest plot of the pooled RR from the fixed-effects model for fatigue in axitinib vs sorafenib treatments. Abbreviations: $\mathrm{Cl}$, confidence interval; $\mathrm{RR}$, risk ratio.

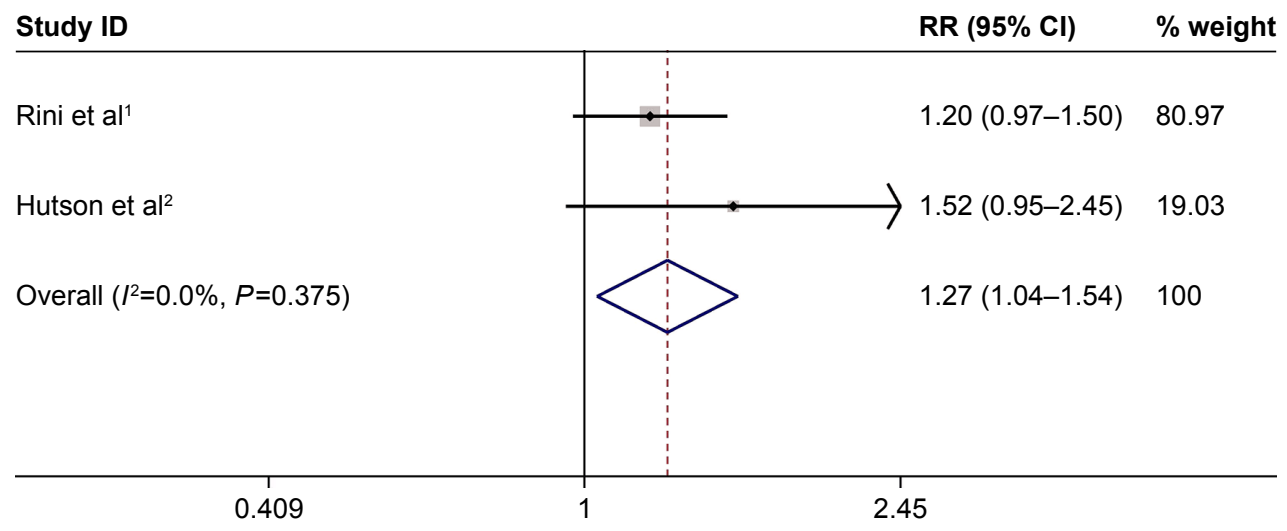

Figure S8 Forest plot showing the pooled RR from the fixed-effects model for decreased appetite in axitinib vs sorafenib treatments. Abbreviations: $\mathrm{Cl}$, confidence interval; $\mathrm{RR}$, risk ratio.

\begin{tabular}{|c|c|c|}
\hline Study ID & $\mathrm{RR}(95 \% \mathrm{Cl})$ & $\%$ weight \\
\hline Rini et al ${ }^{1}$ & $1.19(0.91-1.56)$ & 70.93 \\
\hline Hutson et $\mathrm{al}^{2}$ & $1.52(1.02-2.28)$ & 29.07 \\
\hline Overall $\left(I^{2}=0.0 \%, P=0.317\right)$ & $1.29(1.03-1.61)$ & 100 \\
\hline
\end{tabular}

Figure S9 Forest plot indicating the pooled RR from the fixed-effects model for weight decreased in axitinib vs sorafenib treatments. Abbreviations: $\mathrm{Cl}$, confidence interval; $\mathrm{RR}$, risk ratio. 


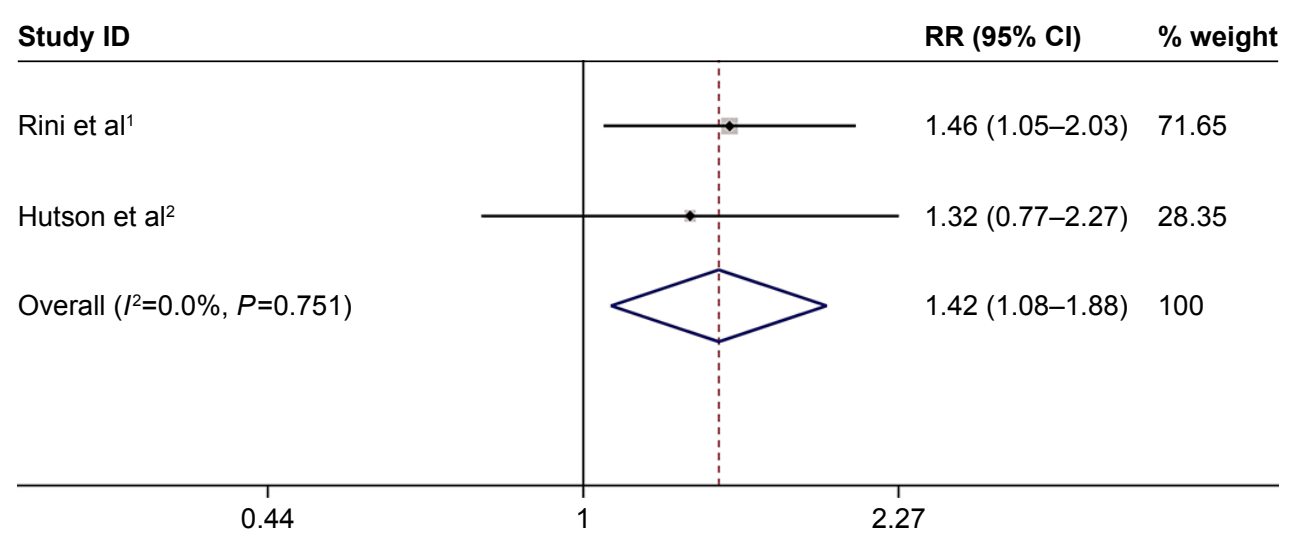

Figure SIO Forest plot presenting the pooled RR from the fixed-effects model for asthenia in axitinib vs sorafenib treatments.

Abbreviations: $\mathrm{Cl}$, confidence interval; $\mathrm{RR}$, risk ratio.

\section{References}

1. Rini BI, Escudier B, Tomczak P, et al. Comparative effectiveness of axitinib versus sorafenib in advanced renal cell carcinoma (axis): a randomised phase 3 trial. Lancet. 2011;378:1931-1939.

2. Hutson TE, Lesovoy V, Al-Shukri S, et al. Axitinib versus sorafenib as first-line therapy in patients with metastatic renal-cell carcinoma: a randomised open-label phase 3 trial. Lancet Oncol. 2013;14:1287-1294.

\section{Publish your work in this journal}

OncoTargets and Therapy is an international, peer-reviewed, open access journal focusing on the pathological basis of all cancers, potential targets for therapy and treatment protocols employed to improve the management of cancer patients. The journal also focuses on the impact of management programs and new therapeutic agents and protocols on

patient perspectives such as quality of life, adherence and satisfaction. The manuscript management system is completely online and includes a very quick and fair peer-review system, which is all easy to use. Visit http://www.dovepress.com/testimonials.php to read real quotes from published authors. 